\title{
Interleukin-21: A New Mediator of Inflammation in Systemic Lupus Erythematosus
}

\author{
Massimiliano Sarra and Giovanni Monteleone \\ Department of Internal Medicine, University Tor Vergata of Rome, 00133 Rome, Italy \\ Correspondence should be addressed to Giovanni Monteleone, gi.monteleone@med.uniroma2.it
}

Received 19 January 2010; Accepted 25 May 2010

Academic Editor: Charles Via

Copyright ( $) 2010$ M. Sarra and G. Monteleone. This is an open access article distributed under the Creative Commons Attribution License, which permits unrestricted use, distribution, and reproduction in any medium, provided the original work is properly cited.

\begin{abstract}
Systemic Lupus Erythematosus (SLE) is an autoimmune disorder characterized by excessive production of a variety of autoantibodies and a wide range of clinical manifestations. Pathogenesis of SLE is complex and not fully understood. There is however evidence that $\mathrm{B}$ and $\mathrm{T}$ cells are critical to the development of disease, and that $\mathrm{T}$ cell-derived cytokines are involved in the SLE-associated inflammatory response. One such cytokine seems to be interleukin (IL)-21, the latest identified member of the $\gamma$-chain-related cytokine family. IL-21 has an important role in the control of the growth, survival, differentiation, and function of both T and B cells, and excessive production of IL-21 has been associated with the development of multiple immune-mediated diseases. Here we review data supporting the involvement of IL-21 in the pathogenesis of SLE.
\end{abstract}

\section{Introduction}

Systemic lupus erythematosus (SLE) is a chronic systemic autoimmune disease with considerable heterogeneity in clinical manifestations and disease course [1]. The etiology of SLE remains unknown, but evidence suggests that SLE results from the interaction of genetic and environmental factors that ultimately promote an abnormal immune response leading to the organ damage [1]. Dysregulation of various components of the immune system can be seen at different stages of SLE development, but hyperactivity of B cells with excessive production of multiple autoantibodies is perhaps the major immunological stigmata of SLE $[2,3]$. The pathogenic role of B cells in SLE is not however strictly linked to the secretion of autoantibodies. B cells can have potent antigen presentation capacity, and they regulate and organize inflammatory responses [4]. Indeed, studies in murine models of SLE have shown that B cells are critical to the development of disease even when they are unable to secrete autoantibodies [5, 6]. Moreover, studies in human SLE showed that the clinical response obtained by treatment of patients with rituximab, a B cell depleting anti-CD20 antibody, preceded autoantibody decline, thus supporting the autoantibody-independent role of B cells in SLE process [7].

A more detailed analysis of molecular mechanisms underlying the SLE-associated tissue damaging-immune response revealed that interactions between $\mathrm{T}$ and $\mathrm{B}$ cells are essential in the development of this disease and that cytokines are key mediators of this interplay [8]. However, because of the redundant functions of cytokines, a major challenge for scientists is to identify key molecule(s) which can profoundly alter the outcome of SLE-associated inflammatory response. Here we discuss whether interleukin (IL)21 is worthy of this description.

\section{IL-21-Producing Cells and Biological Effects of IL-21 on B and T Lymphocytes}

Although IL-21 was initially considered as a cytokine produced by activated peripheral blood $\mathrm{T}$ cells [9], it is now known that it can be synthesized by a range of differentiated CD4+ T helper (Th) cells [10]. Studies in mice have shown that IL-21 is synthesized exclusively by polarized Th17 cells, while in human, IL-21 can also be made by Th1 cells [1116]. Activated NKT cells are another cell source of IL-21 
[17]. More recently, it has been shown that IL-21 is also produced by a subset of CD4+ T cells, which are involved in germinal center (GC) formation and function, and denoted $\mathrm{T}$ follicular helper cells (TFH cells) $[18,19]$. TFH cells express high levels of the chemokine receptor chemokine (C$\mathrm{X}-\mathrm{C}$ motif) receptor 5 (CXCR5), which allows them to home to and be retained by the lymphoid follicle, where contact with antigen-primed B cells promotes B cell proliferation, isotype switching, and somatic mutation of the Ig repertoire $[20,21]$. CD8+ T cells do not normally produce IL-21. However, these cells can synthesize IL-21 if deleted of specific transcription factors, such as T-bet and eomesodermin, and infected with lymphocytic choriomeningitis virus [22].

IL-21 activity is mediated by a heterodimeric receptor, formed by the $\gamma$-chain subunit (shared with IL-2, IL-4, IL-7, IL-9, IL-13, and IL-15 receptors) and its own unique receptor (designated IL-21R) [23, 24]. Binding of IL-21 to the receptor leads to the activation of the Janus-kinase-family proteins (JAK 1 and JAK 3) and signal transducer and activator of transcription (STAT) 1 and STAT3 and, to a lesser degree, STAT4 and STAT5 [10]. IL-21 also activates members of the mitogen-activated protein kinase (MAPK) family such as extracellular signal-regulated protein kinases (ERK) $1 / 2$ in neoplastic cell, epithelial cells, and monocytes $[25,26]$. Strictly linked to the activation of such intracellular pathways is the ability of IL-21 to regulate the functional activity of various immune and non-immune cell types [10]. Here we highlight some of the biological effects of IL-21 on B and T cells, because of the pathogenic role of these cells in SLE. For a detailed description of the regulatory functions of IL-21 on both immune and non-immune cells, the reader is directed towards recent reviews $[10,23,24,27]$.

IL-21 increases B cell proliferation after activation via the $\mathrm{B}$ cell receptor plus $\mathrm{T}$ cell-derived costimulatory signals $[28,29]$. In contrast, IL-21 delivers proapoptotic signals to primary B cells and B cells that are activated with antiIgM or toll-like receptors ligands [30,31]. In cultures of CD40-stimulated human B cells, the proliferative effect of IL-21 is dependent on Stat1 and Stat3 activation [32]. In vitro, stimulation of both murine and human $B$ cells with IL-21 induces the plasma-cell-associated transcription factor B-lymphocyte-induced maturation protein 1, now termed PR domain containing 1 , and subsequent plasma cell differentiation as well as the production of isotypeswitched immunoglobulins (i.e., $\operatorname{IgG}, \operatorname{IgM}$, and $\operatorname{IgA}$ ) $[28,29$, 33]. Importantly, the IL-21-driven generation of memory $B$ cells and plasma cells relies on Stat3, because IL-21 fails to promote the differentiation of Ig-secreting cells in cultures of naïve $\mathrm{B}$ cells isolated from patients with inactivating mutations in Stat3 [32]. Using a well-established model of $\mathrm{B}$ cell differentiation, Avery et al. have also shown that the hen egg lysozyme-specific response of IL-21R-null B cells is diminished compared with wild-type B cells, as indicated by the marked reduction in the number of antigen-specific plasma cells and production of IgM and IgG [32]. Overall, these results suggest that IL-21 and Stat3 play a crucial role in initiating and/or maintaining serological immunity by generating antigen-specific effector $B$ cells from naïve precursors. By contrast, Stat3 does not seem to be necessary for the IL-21-driven isotype switching to IgG [32].

IL-21 is also an important regulator of T cell functions. IL-21 enhances the proliferation of anti-CD3-stimulated $\mathrm{T}$ cells and acts in concert with other common $\gamma$-chaindependent cytokines to enhance the growth of $\mathrm{CD} 4+\mathrm{T}$ cells $[10,24]$. However, IL-21 regulates differently the differentiation and/or maintenance of polarized Th cells depending on the species. Studies in mice revealed that IL-21 can expand either Th2 or Th17 cell responses and inhibit the synthesis of interferon (IFN) $-\gamma[11,12,34-36]$. By contrast, in populations of human peripheral blood or mucosal $\mathrm{T}$ cells that are preactivated with anti-CD3, IL-21 enhances the expression/activation of transcription factors that drive Th1 cell differentiation (i.e., T-bet, Stat4) [14, 37]. IL-21 stimulates the proliferation of CD8+ T cells and synergizes with IL-15 and IL-7 in promoting CD8+ T cell expansion [38-40].

IL-21 seems to have an autocrine role for proper TFH development. Studies in IL-21-deficient mice showed that CXCR5 surface expression on CD4+ T cells is greatly reduced after immunization with a T-cell-dependent antigen, and that IL-21R expression is significantly higher on CXCR5+CD4+ than on CXCR5-CD4+ T cells [19]. GC development is impaired in mice deficient for IL-21 signaling [41]. Adoptive transfer of wild-type CD4+ T cells into IL21R-null recipients followed by immunization rescues GC formation and partially rescues Ig production [19].

\section{Role of IL-21 in Murine Models of SLE}

The fact that IL-21 controls the pool of memory B cells and promotes differentiation of B cells into plasma cells suggests that a deregulated IL-21 activity may contribute to the development of autoimmune diseases. So, many researchers have evaluated the contribution of IL-21 in the pathogenesis of murine models of SLE. Studies from various laboratories have been performed in BXSB.B6-Yaa+/J mice. These strains result from a cross between a C57BL/6 female and an SB/Le male, and the male offspring of the cross had a $50 \%$ mortality rate at 6 months of age [42]. The mice display many of the symptoms common to SLE, including lymphadenopathy, splenomegaly, hypergammaglobulinemia, and severe immune complex-mediated glomerulonephritis [42]. Females of the strain, however, only display a chronic syndrome. Subsequent studies have verified that the disorder is not gonadal hormonally driven but is Y-linked [42]. Analysis of multiple genes in splenocytes taken from these mice revealed a marked age-dependent increase in the levels of IL-21 mRNA as compared to wild-type mice [33]. Corresponding to the increase in IL-21 mRNA, serum levels of IL-21, IgG1, and IgG3 were increased in BXSB.B6-Yaa+/J mice [33]. Importantly, IL-21R-deficient BXSB-Yaa+/J mice show none of the abnormalities characteristic of SLE, thus supporting the key role of IL-21 in the accumulation of plasma cells and production of autoantibodies. In this model, the excessive IL-21 production did not derive from TFH cells, but rather from an extrafollicular population of ICOS+ CD4+ T cells [43]. 
Further support to the pathogenic role of IL-21 in this model of SLE was provided by preclinical studies showing that administration of IL-21R/Fc, a fusion protein neutralizing IL-21, to BXSB.B6-Yaa+ mice results in a decreased production of IL-21, diminished lymphocyte activation, and reduced circulating IgG1 levels [44]. Proteinuria is also reduced in treated mice, but the therapy does not prevent the symptoms of SLE [44]. Moreover, follow-up studies showed that the IL-21 contribution to SLE-like phenotype in BXSB-Yaa mice is variable within the time course of disease progression, because blockade of IL-21 activity in the early phase is deleterious, whereas later in the time course it is advantageous [44]. The reason why the blocking IL-21R/Fc regulates differently the pathogenic inflammatory response in BXSB-Yaa mice remains unknown. In this context, it is noteworthy that IL-21 can exert both inflammatory and anti-inflammatory effects, the latter linked to the induction of IL-10, a counter-regulatory cytokine expressed at high levels both in BXSB-Yaa mice and in human SLE patients [33, 45-47]. Therefore, blockade of IL-21 with IL21R/Fc might inhibit IL-10 expression, thus exacerbating the severity of SLE symptoms in the early phase of the disease.

Studies in MRL-Fas ${ }^{l p r}$ mouse, another model of SLE, showed that blockade of IL-21 with IL-21R/Fc significantly reduced proteinuria, lymphadenopathy, skin lesions, circulating autoantibodies, and IgG1 and IgG2a [48]. In addition, MRL-Fas ${ }^{l p r}$ mice treated with anti IL-21R/Fc showed reduced levels of glomerular IgG deposits in the kidney and no thickening in glomerular basement membranes by histological evaluation [48]. IL-21R/Fc treatment also reduced the number of splenic $\mathrm{T}$ lymphocytes and $\mathrm{B}$ cells antibodies production [48]. In the MRL-Fas ${ }^{l p r}$ mouse, IL-21 is primarily made by an extrafollicular population of ICOSexpressing CD4+ T cells that exhibits reduced expression of P-selectin glycoprotein ligand 1 but is able to produce IL-4 and IFN- $\gamma$ [49].

Evidence for the pathogenic role of IL-21 in SLE also comes from studies in the sanroque mouse strain, in which a mutation in the RING-type ubiquitin ligase protein family member, roquin, results in the accumulation of excessive numbers of both GC and TFH cells with high levels of ICOS, excessive IL-21 production, and severe SLE-like autoimmune phenotype [50]. Lupus-like symptoms are dependent on enhanced GC formation as they could be reduced by deletion of even one allele of the BCL6 gene [51]. However, TFH formation in this model seems to be dependent on ICOS rather than IL-21 [51].

A subpopulation of B- 1 cells expressing the programmed death ligand 2 (termed L2pB-1 cells) has been shown to be enriched for autoreactive immunoglobulin, to be potent in antigen presentation, and to be fully able to facilitate Th1 and Th17 cell differentiation. L2pB1 cells are found in increased numbers in the periphery of mice with SLE and such an increase correlates with anti-DNA antibody levels. This well fits with the demonstration that L2pB-1 cells secrete high levels of autoantibodies, such as dsDNA-reactive antibodies, and can undergo isotype switch and generate IgG1 and IgG2b in the presence of IL-21 [52].

\section{IL-21 in Human SLE}

Little is known about the role of IL-21 in human SLE. Plasma levels of IL-21 are significantly higher in SLE patients than in healthy controls, but IL-21 levels do not seem to correlate with SLE activity [53]. We have recently shown that IL-21 mRNA expression is enhanced in skin biopsies taken from individuals with SLE in comparison to normal controls, even though this increase is less pronounced than that seen in lesional skin of patients with psoriasis [54]. In patients with SLE, IL-21R is under-repressed on total, naïve, and memory $\mathrm{B}$ cells, and on plasmablasts, compared to controls [55]. Reduced levels of IL-21R are associated with nephritis and a high titer of anti-double-stranded DNA antibodies in the serum [55]. By contrast, blood T cells of SLE patients exhibit normal levels of IL-21R [53].

Recent genome-wide association (GWA) studies have shown that single nucleotide polymorphisms (SNPs) in the chromosome 4q27 region containing IL-2 and IL-21 are associated with chronic inflammatory disorders, including inflammatory bowel disease (IBD), celiac disease, psoriasis, diabetes, rheumatoid arthritis, asthma, and SLE, suggesting a common genetic background for these diseases [56-62]. With regard to SLE, a first study genotyped three SNPs in the IL-21 gene in more than 1300 patients with SLE and controls [62]. Two out of the three SNPs (rs907715 and rs2221903) were significantly associated with SLE [62]. Stratification by race revealed that this genetic association was found more in European-American than in African-American SLE patients [62]. The functional consequences of the IL-21 SNPs remain unknown. The fact that both associated SNPs are located within intronal regions of the IL-21 gene suggests however the possibility that they can influence IL-21 production [62]. Another GWA study analyzed 17 SNPs in the IL-21R gene in 2 independent, ethnically divergent populations (European and Hispanic) of SLE patients and controls [63]. A genetic association between rs3093301 (A/G) and SLE was found in both the European-derived and Hispanic cohorts [63]. Moreover, the lupus-risk allele was significantly associated with the presence of malar rash but not other symptoms or signs of SLE [63].

\section{Conclusions}

The involvement of IL-21 in the pathogenic mechanisms causing human SLE remains to be demonstrated. However, both the ability of this cytokine to regulate in vitro and in vivo immunological pathways that are relevant in SLE and the evidence obtained in murine models of SLE suggest that IL-21 could play an important role in the production of pathogenic autoantibodies and end-organ damage in this disease. Therefore, it is tempting to speculate that inhibitors of IL-21 could be useful to attenuate lupus-related clinical manifestations. However, in designing such clinical interventions for blocking IL-21 one should take into consideration not only the advantageous effects but also the risk of potential and deleterious consequences for the host. In fact, it is well-known that, at least under specific circumstances, IL21 can also exert anti-inflammatory actions due to its ability 
to inhibit dendritic cell maturation and stimulate IL-10 production $[45,64]$. In this context, it is also noteworthy that IL-21 may stimulate immune responses against tumor cells and promote CD8+ T cell responses against viruses [65-68]. Therefore, if so, blockade of IL-21 function could attenuate antineoplastic immunity and wake worse the course of viral infections.

\section{References}

[1] A. Rahman and D. A. Isenberg, "Systemic lupus erythematosus," New England Journal of Medicine, vol. 358, no. 9, pp. 929939, 2008.

[2] J. Anolik and I. Sanz, "B cells in human and murine systemic lupus erythematosus," Current Opinion in Rheumatology, vol. 16, no. 5, pp. 505-512, 2004.

[3] G. Nagy, A. Koncz, and A. Perl, "T- and B-cell abnormalities in systemic lupus erythematosus," Critical Reviews in Immunology, vol. 25, no. 2, pp. 123-140, 2005.

[4] D. Rodríguez-Pinto, "B cells as antigen presenting cells," Cellular Immunology, vol. 238, no. 2, pp. 67-75, 2005.

[5] O. T. M. Chan, L. G. Hannum, A. M. Haberman, M. P. Madaio, and M. J. Shlomchik, "A novel mouse with B cells but lacking serum antibody reveals an antibody-independent role for B cells in murine lupus," Journal of Experimental Medicine, vol. 189, no. 10, pp. 1639-1648, 1999.

[6] O. T. M. Chan, M. P. Madaio, and M. J. Shlomchik, "B cells are required for lupus nephritis in the polygenic, Fas-intact MRL model of systemic autoimmunity," Journal of Immunology, vol. 163, no. 7, pp. 3592-3596, 1999.

[7] J. H. Anolik, J. Barnard, A. Cappione et al., "Rituximab improves peripheral B cell abnormalities in human systemic lupus erythematosus," Arthritis and Rheumatism, vol. 50, no. 11, pp. 3580-3590, 2004.

[8] A. Perl, D. R. Fernandez, T. Telarico, E. Doherty, L. Francis, and P. E. Phillips, "T-cell and B-cell signaling biomarkers and treatment targets in lupus," Current Opinion in Rheumatology, vol. 21, no. 5, pp. 454-464, 2009.

[9] J. Parrish-Novak, S. R. Dillon, A. Nelson et al., "Interleukin 21 and its receptor are involved in NK cell expansion and regulation of lymphocyte function," Nature, vol. 408, no. 6808, pp. 57-63, 2000.

[10] G. Monteleone, F. Pallone, and T. T. Macdonald, "Interleukin21 as a new therapeutic target for immune-mediated diseases," Trends in Pharmacological Sciences, vol. 30, no. 8, pp. 441-447, 2009.

[11] T. Korn, E. Bettelli, W. Gao et al., "IL-21 initiates an alternative pathway to induce proinflammatory T H17 cells," Nature, vol. 448, no. 7152, pp. 484-487, 2007.

[12] L. Yang, D. E. Anderson, C. Baecher-Allan et al., "IL-21 and TGF- $\beta$ are required for differentiation of human T H17 cells," Nature, vol. 454, no. 7202, pp. 350-352, 2008.

[13] L. Zhou, I. I. Ivanov, R. Spolski et al., "IL-6 programs TH-17 cell differentiation by promoting sequential engagement of the IL-21 and IL-23 pathways," Nature Immunology, vol. 8, no. 9, pp. 967-974, 2007.

[14] G. Monteleone, I. Monteleone, D. Fina et al., "Interleukin21 enhances T-helper cell type I signaling and interferon- $\gamma$ production in Crohn's disease," Gastroenterology, vol. 128, no. 3, pp. 687-694, 2005.

[15] X. Zhu, D. Ma, J. Zhang et al., "Elevated interleukin-21 correlated to Th17 and Th1 cells in patients with immune thrombocytopenia," Journal of Clinical Immunology, vol. 30, no. 2, pp. 253-259, 2010.

[16] M. Sarra, C. Stolfi, M. C. Fantini, et al., "Interferon-gammaexpressing cells are the major source of interleukin-21 in inflammatory bowel disease," Inflammatory Bowel Diseases. In press.

[17] J. M. Coquet, K. Kyparissoudis, D. G. Pellicci et al., "IL-21 is produced by NKT cells and modulates NKT cell activation and cytokine production," Journal of Immunology, vol. 178, no. 5, pp. 2827-2834, 2007.

[18] V. L. Bryant, C. S. Ma, D. T. Avery et al., "Cytokine-mediated regulation of human $\mathrm{B}$ cell differentiation into Ig-secreting cells: predominant role of IL-21 produced by CXCR5+ T follicular helper cells," Journal of Immunology, vol. 179, no. 12, pp. 8180-8190, 2007.

[19] A. Vogelzang, H. M. McGuire, D. Yu, J. Sprent, C. R. Mackay, and C. King, "A fundamental role for interleukin-21 in the generation of T follicular helper cells," Immunity, vol. 29, no. 1, pp. 127-137, 2008.

[20] R. Spolski and W. J. Leonard, "IL-21 and T follicular helper cells," International Immunology, vol. 22, no. 1, pp. 7-12, 2010.

[21] N. Fazilleau, L. Mark, L. J. McHeyzer-Williams, and M. G. McHeyzer-Williams, "Follicular helper T cells: lineage and location," Immunity, vol. 30, no. 3, pp. 324-335, 2009.

[22] A. M. Intlekofer, A. Banerjee, N. Takemoto et al., "Anomalous type 17 response to viral infection by CD8+ T cells lacking Tbet and eomesodermin," Science, vol. 321, no. 5887, pp. 408411, 2008.

[23] R. Spolski and W. J. Leonard, "The Yin and Yang of interleukin-21 in allergy, autoimmunity and cancer," Current Opinion in Immunology, vol. 20, no. 3, pp. 295-301, 2008.

[24] G. Monteleone, F. Pallone, and T. T. MacDonald, "Interleukin21: a critical regulator of the balance between effector and regulatory T-cell responses," Trends in Immunology, vol. 29, no. 6, pp. 290-294, 2008.

[25] R. Caruso, D. Fina, I. Peluso et al., "A functional role for interleukin-21 in promoting the synthesis of the T-cell chemoattractant, MIP- $3 \alpha$, by gut epithelial cells," Gastroenterology, vol. 132, no. 1, pp. 166-175, 2007.

[26] C. F. Fuqua, R. Akomeah, J. O. Price, and S. E. Adunyah, "Involvement of ERK-1/2 in IL-21-induced cytokine production in leukemia cells and human monocytes," Cytokine, vol. 44, no. 1, pp. 101-107, 2008.

[27] R. Spolski and W. J. Leonard, "Interleukin-21: basic biology and implications for cancer and autoimmunity," Annual Review of Immunology, vol. 26, pp. 57-79, 2008.

[28] R. Ettinger, S. Kuchen, and P. E. Lipsky, "The role of IL21 in regulating B-cell function in health and disease," Immunological Reviews, vol. 223, no. 1, pp. 60-86, 2008.

[29] D. Konforte, N. Simard, and C. J. Paige, "IL-21: an executor of B cell fate," Journal of Immunology, vol. 182, no. 4, pp. 17811787, 2009.

[30] H. Jin, R. Carrio, A. Yu, and T. R. Malek, "Distinct activation signals determine whether IL-21 induces B cell costimulation, growth arrest, or Bim-dependent apoptosis," Journal of Immunology, vol. 173, no. 1, pp. 657-665, 2004.

[31] D. S. Mehta, A. L. Wurster, M. J. Whitters, D. A. Young, M. Collins, and M. J. Grusby, "IL-21 induces the apoptosis of resting and activated primary B cells," Journal of Immunology, vol. 170, no. 8, pp. 4111-4118, 2003.

[32] D. T. Avery, E. K. Deenick, C. S. Ma et al., "B cell-intrinsic signaling through IL-21 receptor and STAT3 is required for establishing long-lived antibody responses in humans," 
Journal of Experimental Medicine, vol. 207, no. 1, pp. 155-171, 2010.

[33] K. Ozaki, R. Spolski, R. Ettinger et al., "Regulation of B cell differentiation and plasma cell generation by IL-21, a novel inducer of Blimp-1 and Bcl-6," Journal of Immunology, vol. 173, no. 9, pp. 5361-5371, 2004.

[34] A. Fröhlich, B. J. Marsland, I. Sonderegger et al., "IL-21 receptor signaling is integral to the development of Th2 effector responses in vivo," Blood, vol. 109, no. 5, pp. 2023 2031, 2007.

[35] J. Pesce, M. Kaviratne, T. R. Ramalingam et al., "The IL21 receptor augments Th2 effector function and alternative macrophage activation," Journal of Clinical Investigation, vol. 116, no. 7, pp. 2044-2055, 2006.

[36] D. Fina, M. Sarra, M. C. Fantini et al., "Regulation of gut inflammation and Th17 cell response by interleukin-21," Gastroenterology, vol. 134, no. 4, pp. 1038-1048, 2008.

[37] M. Strengeil, T. Sareneva, D. Foster, I. Julkunen, and S. Matikainen, "IL-21 up-regulates the expression of genes associated with innate immunity and Th1 response," Journal of Immunology, vol. 169, no. 7, pp. 3600-3605, 2002.

[38] W. J. Leonard, R. Zeng, and R. Spolski, "Interleukin 21: a cytokine/cytokine receptor system that has come of age," Journal of Leukocyte Biology, vol. 84, no. 2, pp. 348-356, 2008.

[39] S. Liu, G. Lizée, Y. Lou et al., "IL-21 synergizes with IL-7 to augment expansion and anti-tumor function of cytotoxic T cells," International Immunology, vol. 19, no. 10, pp. 12131221, 2007.

[40] R. Zeng, R. Spolski, S. E. Finkelstein et al., "Synergy of IL-21 and IL-15 in regulating CD8+ T cell expansion and function," Journal of Experimental Medicine, vol. 201, no. 1, pp. 139-148, 2005.

[41] K. Ozaki, R. Spolski, C. G. Feng et al., "A critical role for IL-21 in regulating immunoglobulin production," Science, vol. 298, no. 5598, pp. 1630-1634, 2002.

[42] S. Izui, N. Ibnou-Zekri, L. Fossati-Jimack, and M. Iwamoto, "Lessons from BXSB and related mouse models," International Reviews of Immunology, vol. 19, no. 4-5, pp. 447-472, 2000.

[43] J. A. Bubier, T. J. Sproule, O. Foreman et al., "A critical role for IL-21 receptor signaling in the pathogenesis of systemic lupus erythematosus in BXSB-Yaa mice," Proceedings of the National Academy of Sciences of the United States of America, vol. 106, no. 5, pp. 1518-1523, 2009.

[44] J. A. Bubier, S. M. Bennett, T. J. Sproule et al., "Treatment of BXSB-Yaa mice with IL-21R-Fc fusion protein minimally attenuates systemic lupus erythematosus," Annals of the New York Academy of Sciences, vol. 1110, pp. 590-601, 2007.

[45] R. Spolski, H. P. Kim, W. Zhu, D. E. Levy, and W. J. Leonard, "IL-21 mediates suppressive effects via its induction of IL-10," Journal of Immunology, vol. 182, no. 5, pp. 2859-2867, 2009.

[46] L. Llorente, Y. Richaud-Patin, J. Wijdenes et al., "Spontaneous production of interleukin-10 by B lymphocytes and monocytes in systemic lupus erythematosus," European Cytokine Network, vol. 4, no. 6, pp. 421-427, 1993.

[47] L. Llorente, W. Zou, Y. Levy et al., "Role of interleukin 10 in the B lymphocyte hyperactivity and autoantibody production of human systemic lupus erythematosus," Journal of Experimental Medicine, vol. 181, no. 3, pp. 839-844, 1995.

[48] D. Herber, T. P. Brown, S. Liang, D. A. Young, M. Collins, and K. Dunussi-Joannopoulos, "IL-21 has a pathogenic role in a lupus-prone mouse model and its blockade with IL-21R.Fc reduces disease progression," Journal of Immunology, vol. 178, no. 6, pp. 3822-3830, 2007.
[49] J. M. Odegard, B. R. Marks, L. D. Diplacido et al., "ICOSdependent extrafollicular helper T cells elicit IgG production via IL-21 in systemic autoimmunity," Journal of Experimental Medicine, vol. 205, no. 12, pp. 2873-2886, 2008.

[50] C. G. Vinuesa, M. C. Cook, C. Angelucci et al., "A RING-type ubiquitin ligase family member required to repress follicular helper T cells and autoimmunity," Nature, vol. 435, no. 7041, pp. 452-458, 2005.

[51] M. A. Linterman, R. J. Rigby, R. K. Wong et al., "Follicular helper T cells are required for systemic autoimmunity," Journal of Experimental Medicine, vol. 206, no. 3, pp. 561-576, 2009.

[52] X. Zhong, S. Lau, C. Bai et al., "A novel subpopulation of B1 cells is enriched with autoreactivity in normal and lupusprone mice," Arthritis and Rheumatism, vol. 60, no. 12, pp. 3734-3743, 2009.

[53] C. K. Wong, P. T. Y. Wong, L. S. Tam, E. K. Li, D. P. Chen, and C. W. K. Lam, "Elevated production of B cell chemokine CXCL13 is correlated with systemic lupus erythematosus disease activity," Journal of Clinical Immunology, vol. 30, no. 1, pp. 45-52, 2010.

[54] R. Caruso, E. Botti, M. Sarra et al., "Involvement of interleukin-21 in the epidermal hyperplasia of psoriasis," Nature Medicine, vol. 15, no. 9, pp. 1013-1015, 2009.

[55] H. Mitoma, T. Horiuchi, Y. Kimoto et al., "Decreased expression of interleukin-21 receptor on peripheral B lymphocytes in systemic lupus erythematosus," International Journal of Molecular Medicine, vol. 16, no. 4, pp. 609-615, 2005.

[56] E. A. M. Festen, P. Goyette, R. Scott et al., "Genetic variants in the region harbouring IL2/IL21 associated with ulcerative colitis," Gut, vol. 58, no. 6, pp. 799-804, 2009.

[57] D. A. van Heel, L. Franke, K. A. Hunt et al., "A genome-wide association study for celiac disease identifies risk variants in the region harboring IL2 and IL21," Nature Genetics, vol. 39, no. 7, pp. 827-829, 2007.

[58] Y. Liu, C. Helms, W. Liao et al., "A genome-wide association study of psoriasis and psoriatic arthritis identifies new disease loci," PLoS Genetics, vol. 4, no. 3, Article ID e1000041, 2008.

[59] K. Asano, H. Ikegami, T. Fujisawa et al., "Molecular scanning of interleukin-21 gene and genetic susceptibility to type 1 diabetes," Human Immunology, vol. 68, no. 5, pp. 384-391, 2007.

[60] V. H. Teixeira, C. Pierlot, P. Migliorini et al., "Testing for the association of the KIAA1109/Tenr/IL2/IL21 gene region with rheumatoid arthritis in a European family-based study," Arthritis Research and Therapy, vol. 11, no. 2, article R45, 2009.

[61] R. Chatterjee, J. Batra, and B. Ghosh, "A common exonic variant of interleukin 21 confers susceptibility to atopic asthma," International Archives of Allergy and Immunology, vol. 148, no. 2, pp. 137-146, 2009.

[62] A. H. Sawalha, K. M. Kaufman, J. A. Kelly et al., "Genetic association of interleukin-21 polymorphisms with systemic lupus erythematosus," Annals of the Rheumatic Diseases, vol. 67, no. 4, pp. 458-461, 2008.

[63] R. Webb, J. T. Merrill, J. A. Kelly et al., "A polymorphism within IL21R confers risk for systemic lupus erythematosus," Arthritis and Rheumatism, vol. 60, no. 8, pp. 2402-2407, 2009.

[64] K. Brandt, S. Bulfone-Paus, D. C. Foster, and R. Rückert, "Interleukin-21 inhibits dendritic cell activation and maturation,” Blood, vol. 102, no. 12, pp. 4090-4098, 2003.

[65] D. J. Andorsky and J. M. Timmerman, "Interleukin-21: biology and application to cancer therapy," Expert Opinion on Biological Therapy, vol. 8, no. 9, pp. 1295-1307, 2008. 
[66] H. Elsaesser, K. Sauer, and D. G. Brooks, "IL-21 is required to control chronic viral infection," Science, vol. 324, no. 5934, pp. 1569-1572, 2009.

[67] A. Fröhlich, J. Kisielow, I. Schmitz et al., "IL-21R on T cells is critical for sustained functionality and control of chronic viral infection,” Science, vol. 324, no. 5934, pp. 1576-1580, 2009.

[68] J. S. Yi, M. Du, and A. J. Zajac, "A vital role for interleukin-21 in the control of a chronic viral infection," Science, vol. 324, no. 5934, pp. 1572-1576, 2009. 


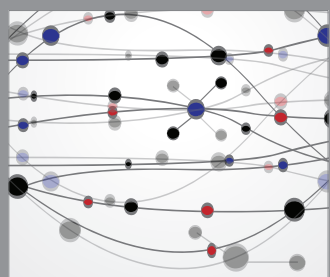

The Scientific World Journal
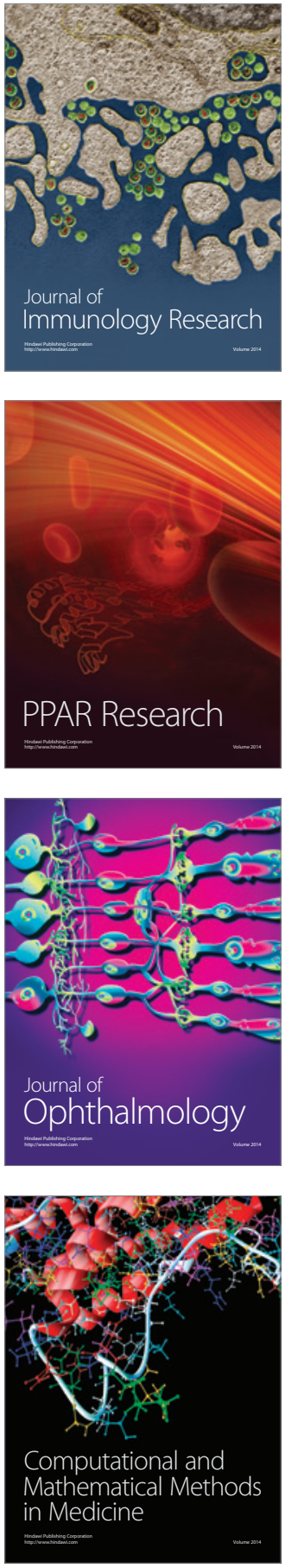

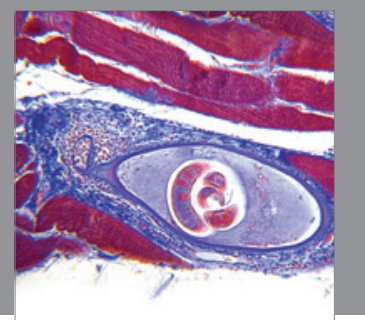

Gastroenterology

Research and Practice
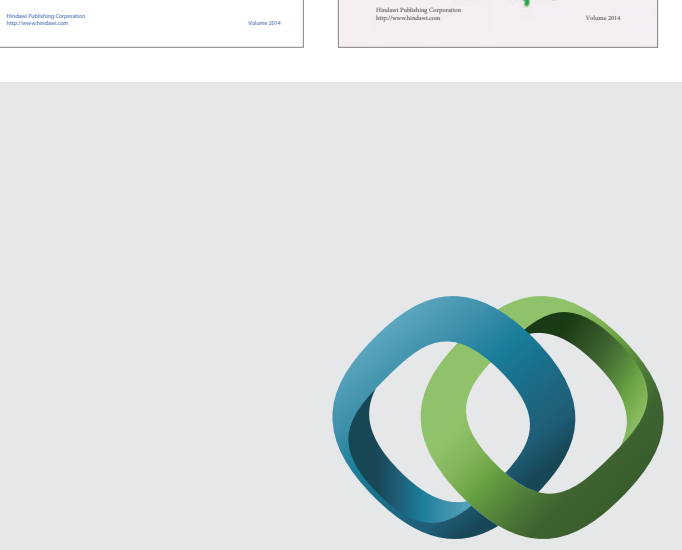

\section{Hindawi}

Submit your manuscripts at

http://www.hindawi.com
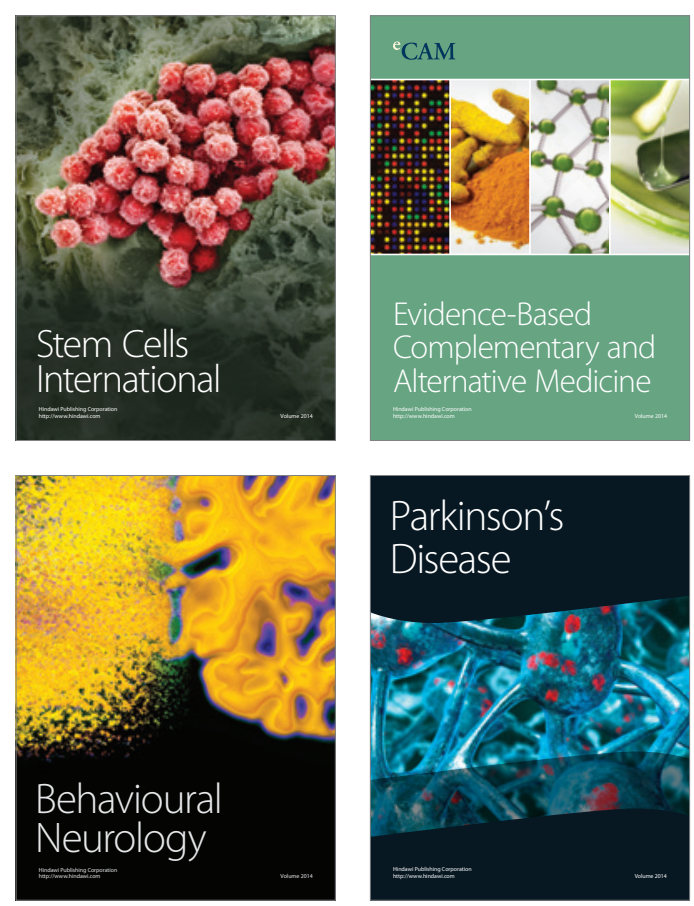

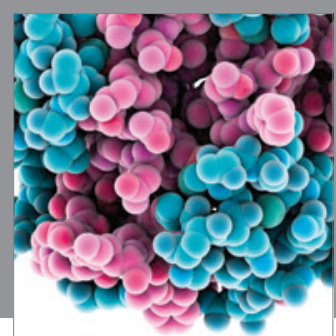

Journal of
Diabetes Research

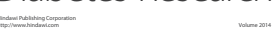

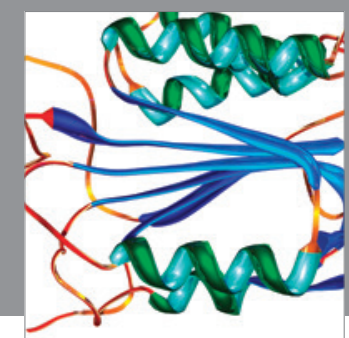

Disease Markers
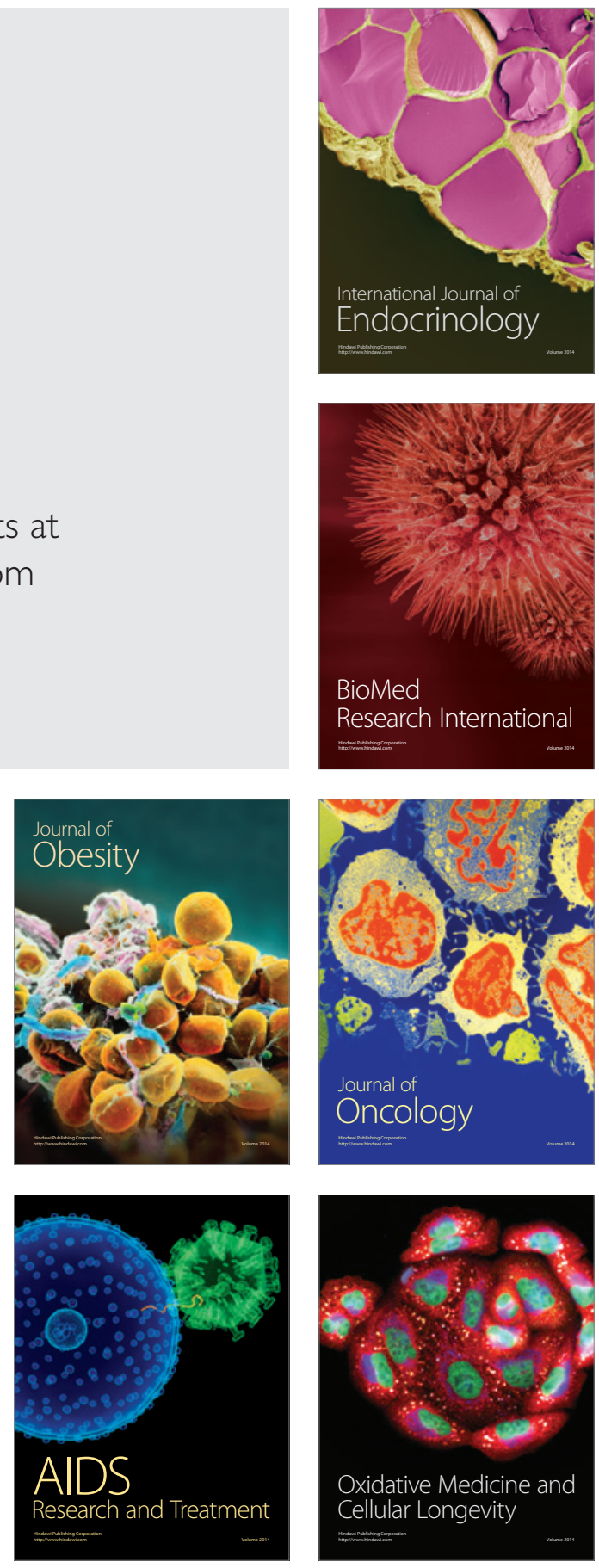